\title{
Collusion and Delegation
}

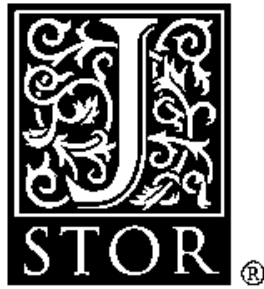

Jean-Jacques Laffont; David Martimort

The RAND Journal of Economics, Vol. 29, No. 2 (Summer, 1998), 280-305.

Stable URL:

http://links.jstor.org/sici?sici=0741-6261\%28199822\%2929\%3A2\%3C280\%3ACAD\%3E2.0.CO\%3B2-H

The RAND Journal of Economics is currently published by The RAND Corporation.

Your use of the JSTOR archive indicates your acceptance of JSTOR's Terms and Conditions of Use, available at http://www.jstor.org/about/terms.html. JSTOR's Terms and Conditions of Use provides, in part, that unless you have obtained prior permission, you may not download an entire issue of a journal or multiple copies of articles, and you may use content in the JSTOR archive only for your personal, non-commercial use.

PIease contact the publisher regarding any further use of this work. Publisher contact information may be obtained at http://www.jstor.org/journals/rand.htmI.

Each copy of any part of a JSTOR transmission must contain the same copyright notice that appears on the screen or printed page of such transmission.

ISTOR is an independent not-for-profit organization dedicated to creating and preserving a digital archive of scholarly journals. For more information regarding JSTOR, please contact jstor-info@umich.edu. 


\title{
Collusion and delegation
}

\author{
Jean-Jacques Laffont* \\ and
}

David Martimort**

We discuss the internal organization of the firm, arguing that the comparison between a centralized and a decentralized hierarchical organization should be cast in terms of the agency costs associated with the different side-contracting games that agents play in these organizations. In our model, with no limits on communication between the agents and the principal (complete contracting), collusion is not an issue in a centralized organization. Centralization always dominates (at least weakly) delegation. With limits on communication (incomplete contracting), collusion may have some bite under centralization. Limits on communication introduce an anonymity condition on the contract, creating a conflict between participation and coalition incentive constraints under centralization. By shifting the bargaining power in the side-contracting stage, delegation is nonanonymous and asymmetric by design. This conflict is then avoided or diminished depending on the exact timing of the delegation game.

\section{Introduction}

A major debate in the theory of the firm concerns its proper degree of decentralization. In most firms, a large part of the information relevant for decision making is dispersed among the members of the firm. The goal of organizational design is to set up the communication channels and to allocate authority in order to use this information in the least costly way. Under delegation, the agents of the periphery have no direct communication with the center. Reports on their information must flow up a hierarchy and then recommendations from the center flow down, Ieaving some decision-making authority at several levels of the hierarchy. Hierarchies are deep and agents receive asymmetric compensations and different levels of authority and responsibility, depending on their ranking in the hierarchy. In contrast, under centralization, the agents of the periphery communicate directly with the center, which centralizes all decision making. Hierarchies are rather flat, and agents at the same level of the hierarchy receive the same compensation schemes and have the same amount of authority.

* IDEJ and GREMAQ, Université de Toulouse I, France; laffont@cict.fr.

** IDEI and ESR-INRA Toulouse, France; martimor@toulouse.inra.fr.

We thank seminar participants at Cirano MontreaI and at the Universities of Copenhagen and Vienna, Giacinta Cestone, Antonio Estache, Bruno Jullien, Trond Olsen, three anonymous referees, and the Editor Mike Riordan for helpful comments on earlier versions of this article. We are responsible for any' error. 
What are the costs and benefits of each of these different organizations of the firm? How are incentive problems solved under each of those arrangements? What is the exact impact of communication constraints in each case? For a given distribution of asymmetric information within the firm, what should be its optimal internal organization?

Answering these questions is not only important for the internal design of the firm; it allows us to better understand the behavior of the economy as a whole. The recent trend toward flatter organizational forms inside the firm, ${ }^{1}$ the shrinking share of the government sector in all Western economies, and the failures of the socialist economies ${ }^{2}$ are all hard evidence that the debate over the optimal level of decentralization in organizations has never been so necessary.

Under its standard formulation, the theory of incentives faces indeed a challenge in dealing with these difficult issues. The revelation principle (Gibbard (1973), Green and Laffont (1977), and Myerson (1979), among many others) tells us that any allocation of resources obtained with a decentralized mechanism between the members of an organization can be equivalently implemented within a centralized structure. In such a structure, each agent communicates his information directly to a mediator or principal and receives contingent plans of actions in return. Therefore, the revelation principle says that, under the assumptions of self-interested behavior by all members of the firm and perfect communication with the principal, there is no scope for a hierarchical design of communication channels within the organization. More precisely, any set of bilateral contracts linking the agents together is, at least weakly, dominated by a centralized grand-contract with the principal.

The comerstone of this argument is based on a pair of particular assumptions about communication costs. First, in a decentralized organization agents can, by definition, communicate among themselves, but under centralization, the principal has full control of the communication technology. Any bilateral communication between agents can be prevented at no cost or alternatively is infinitely costly. Hence, no binding agreement between the members of an organization is feasible on top of the grand-contract offered by the principal, and their behavior is fully noncooperative. Agents cannot coordinate their messages in the grand-contract, and this justifies their Bayesian-Nash behavior in information reporting. This assumption is clearly questionable in view of the evidence on collusive behavior well documented by sociological studies of the internal organization of the firm.

Analyzing the issue of collusion brings us closer to a more realistic view of the relationship between separate units of the firm. For instance, Dalton (1959) has emphasized that various cliques form within the firm. The so-called horizontal cliques involve groups of managers or workers sharing a common interest who act as informal associations willing "to increase their status, their rewards or to get more support for their job activities." They may, for instance, be reluctant to enforce changes in production on the work place, or they may be willing to develop some norms of reciprocity that allow exchanges of favors among them, as Gouldner (1961) has emphasized. These cliques cut across departments and embrace formal equals. In his study of the bureaucracy phenomenon, Crozier (1963) argued that large firms were also subject to the emergence of some vertical cliques between supervisors and workers. ${ }^{3}$ Vertical cliques are up-and-down alliances between formal unequals, such as a top officer and his subordinate.

\footnotetext{
'See Holmström (1996) for a discussion of these issues

${ }^{2}$ See Stiglitz $(1994$, chapter 10) for a discussion of the centralization versus decentralization problems in this context.

${ }^{3}$ See Tirole (1986) and (1992) for models describing this vertical collusive behavior between supervisors and supervisees in organizations using the methodology of hard information.
} 
The second assumption of zero communication cost with the principal is also problematic in view of the first one. Indeed, the revelation principle assumes that communication between the principal and the agents is unlimited and costless. Any comparison between different organizational forms should be based on a more coherent set of assumptions on communication in the organization.

The insight provided by this article is that the decentralization puzzle might be understood once collusive behavior among agents of the organization and limits on communication are both taken into account. In our model, with any of these assumptions alone, the puzzle remains and centralization still dominates delegation, at least weakly. Under limited communication, different organizations of the firm provide different opportunities for side contracting and allocate differently the bargaining power in the side-contracting stage. These differences in side contracting yield differences in the firm's overall efficiency.

To make this point, we analyze an intrafirm procurement model. A firm must produce a final widget from a two-stage production process. Each of these production stages is performed by an independent unit or department that produces an essential input. Hence, there is perfect complementarity in production. Each unit is privately informed of its production cost. For a given organizational structure, the problem of the firm's top manager (namely, the principal) is to find the best production levels knowing the agents' incentives to overreport their costs and the possible limits of communication he faces. Our model can thus be seen as a rough picture of the organizational problem faced by the CEO of a large firm when dealing with several internal input suppliers. Alfred Chandler, for instance, has reported (interview in the Journal of Applied Corporate Finance, Fall 1993) that the CEO of General Electric had totally lost control of its different subunits because of the increasing size of the company by the end of the $1960 \mathrm{~s}$. The strategic planning decision was overly bureaucratized, decision making became absolutely inefficient, and the hierarchy was too deep. ${ }^{4}$ The firm. was subject to an enormous amount of number manipulation on each one of its line of mature activities, and this resulted in bad overall performance. A new CEO's organizational response to these problems was first to improve control by flattening the hierarchy and second to cut GE's business into three groups: "core," "services," and "high technology," each under decentralized control. According to Chandler, this approach of multilateral intermediate management proved to be effective in coping with the incentive problems.

In an interesting survey of the insights learned from the principal-agent literature in the field of accounting, Baiman (1982) stresses that lessons from the single-agent model may not hold with more than two agents, and that complexities in the design of transfer-pricing schemes are introduced by the potential for coalitional behavior between selling and buying units. In fact, since our model discusses the optimal allocation of resources within the firm, it also provides insights on the choice of different transfer-pricing modes. Following the terminology presented in Eccles (1985), a centralized organization corresponds to an organization using a system of dual transfer pricing in which each unit receives a specific transfer from the central headquarters. By contrast, under delegation the decision on which transfer price to use to regulate the exchange of the intermediate good is left to the buying unit. In Eccles' vocabulary, market agency emerges.

Our model may also shed some light on the optimal regulation of several regulated industries using product components that are combined to produce the final good or service. In the field of electricity, a public utility regulated for the transmission of

"To quote Chandler precisely, "The business plans were originated from planners in the business units and then passed up to three other levels of planners at higher levels of the organization." 
electricity is forced by the Public Utility Regulation Policies Act (1978) to contract for the provision of bulk power with an independent power producer. An important question for evaluating the scope of regulation is whether this contractual relationship should be also regulated under a centralized arrangement or should be left unregulated under delegation.

To address this question of the appropriate depth of the hierarchy, we consider two very stylized organizations of the firm. In the first one, centralization, the central headquarters controls a flat hierarchy and contracts directly with both input suppliers. However, the principal cannot stop these informed agents from communicating among themselves. Communication not only flows up and down but also laterally between the two input suppliers. Lateral communication between the agents is the source of their ability to enforce their collusive behavior. This allows them to collude to promote their collective interests against that of the principal.

Under delegation, the central headquarters instead contracts first with one input supplier, say $A_{1}$. This agent receives a compensation scheme linking the outcome of the production process to some monetary reward. He also receives the right to subcontract with the other input supplier, $A_{2}$, and we assume that he becomes the (side-) principal in his relations with $A_{2}$. This incentive package includes in particular the right to offer and design an incentive payment to this second agent. This contractual arrangement, or inside contracting system, corresponds to a steep hierarchy. The length of the chain of command between the principal and the bottom of the hierarchy increases. Since there is no direct communication between the principal and agent $\boldsymbol{A}_{2}$, this structure may therefore be subject to a loss of control associated with a longer chain of command, as Williamson (1985) has argued.

Taking into account both the issues of limits on communication and side contracting puts $u s$ in a third-best world that is more complicated than the second-best setting analyzed by standard incentive theory. In our model, with no limit on communication, collusion-proofness does not create any further cost in the centralized organization. The third-best outcome is also the second-best outcome corresponding to noncooperative behavior between the agents. Delegation is also no more costly when the middle principal accepts the grand-contract before knowing the bottom agent's type. It is indeed possible for the principal to offer a system of transfers that makes $A_{\mathrm{I}}$ residual claimant for the whole hierarchy's surplus.

Nevertheless, one of the main arguments heard to justify delegation is that it may help when information is hard and cumbersome to process. With limits on communication between the agents and the principal, the latter cannot contract on the precise decomposition of the agents' vector of types but only on a rough statistic: the sum of their production costs. In other words, the incentive contract offered by the headquarters to the suppliers can be contingent on their production level but not on their relative efficiency or on their identity. The limit on communication requires the grand-contract to be anonymous. With such a constraint and when collusion is not an issue, delegation is (at least weakly) still dominated by centralization. But, this limit on communication also introduces some scope for collusive behavior between the agents that undermines the efficiency of a centralized organization. Delegation then dominates. This strict superiority of a hierarchy over centralization is obtained not by the force of communication costs, but by the interplay of limited communication and coalition incentive constraints. In fact, with limits on communication, anonymity between the agents introduces a tension between coalition incentive and participation constraints under centralization. Because communication flows up the hierarchy and information is revealed sequentially within the organization, delegation may harden coalition incentive constraints. But delegation, by shifting the bargaining power toward the middle principal, also makes it easier to satisfy participation constraints. When the middle principal still 
accepts the grand-contract offered by the principal at the interim stage, i.e., before knowing the subcontractor's type, delegation entails no loss with respect to the secondbest outcome. The limit on communication does not keep the principal from making the middle principal the residual claimant for the hierarchy's profit. When acceptance of the contract is made after the learning of $A_{2}{ }^{\prime}$ 's type, delegation entails a strictly positive loss of control due to the double rent-extraction along the hierarchy. Nevertheless, the advantage of an asymmetric organization design is such that delegation may possibly continue to dominate when the double rent-extraction phenomenon does not matter too much.

More generally, our results also hold when we replace our assumption of limited communication by a more exogenous symmetry or "fairness" restriction imposed on the grand-mechanism offered by the principal under centralization. The dominance of delegation can then be interpreted as saying that asymmetry between the agents in an organization helps, since it breaks the faimess restriction.

We share, with several trends of the literature, our goal of comparing different internal organizations of the firm when information is spread among agents. Like the recent literature on network architectures and in particular Radner (1993), Bolton and Dewatripont (1994), and Van Zandt (1996), we stress that limits on communication matter in the design of the organization. We also argue that incentive problems are important and that the span and the length of the hierarchy matter for incentives. ${ }^{5}$ In this sense, our article is close to Melumad, Mookherjee, and Reichelstein (1992), who also stress that delegation may help when the contracting environment is restricted. Unlike these authors, we do not stress that individual incentive problems are harder to solve with limits on communication. In our model, under the assumption of self-interested behavior, the optimal contract still achieves the second best even with limits on communication. Our analysis shows instead that some quite new incentive problems arise from the interaction of limits on communication and coalition incentive constraints. Allowing collusion under centralization also differentiates our article from other comparisons of centralized versus decentralized arrangements that can be found in the literature, in particular Melumad, Mookherjee, and Reichelstein (1992) and (1995), McAfee and McMillan (1995), Gilbert and Riordan (1995), and Baron and Besanko (1992), among others. ${ }^{6}$ This literature has mostly discussed the losses involved in a decentralized arrangement. We argue instead that centralization comes with its own costs: the costs of internal side contracting.

The article is organized as follows. Section 2 presents the model with the timings of the two side-contracting games we envision: centralization and delegation. We discuss therein our modelling options to describe the impact of collusive behavior between the input suppliers under centralization. As a first benchmark, Section 3 analyzes the case of unlimited communication between the agents and the principal. We show that collusion has no bite in this setting and that centralization is therefore an optimal organizational choice for the principal. Delegation also implements this second-best outcome and thus performs as well as centralization. Section 4 introduces our assumption of limited communication and discusses how this assumption constrains the set of available contracts. We show that delegation still implements the second best but centralization now does strictly worse. Section 5 discusses some variations for the assumptions of our model. First, we discuss two other assumptions imposing anonymity

s See Williamson (1967), Calvo and Wellisz (1978), and Qian (1994) for some work along these lines Contrary to this literature, we do not assume per se that a large span of control induces less-efficient monitoring.

${ }^{6}$ See also Mirrlees (1976), Macho-Stadler and Perez-Castrillo (1990), and Balliga and Sjostrom (1996) for models of delegation in a moral hazard environment. Felli (1997) analyzes delegation with adverse selection but does not compare the efficiency of this arrangement with a more centralized organization. 
without using limits on communication: the first one is that the grand-contract has to satisfy a fairness requirement; the second is that the coalition can impose this equality of treatment by elaborating a more complex strategy. Next, we analyze the case where information is verifiable between the agents. Collusion and delegation now take place under symmetric information between the agents. Then we analyze a timing of the delegation game in which acceptance of the grand-contract by the intermediate level of the hierarchy occurs after the learning of the subcontractor's cost. Section 6 briefly concludes by proposing some possible extensions.

\section{The model}

Technology and preferences. We consider a firm made of three agents: a headquarters or principal $P$ and two suppliers of inputs essential to perform the two-stage production process within the firm. When the principal wants to produce a quantity $q$ of final good, agent $A_{1}$ produces a quantity $q_{1}$ of an intermediate good (good 1), which $A_{2}$ uses to produce a quantity $q_{2}$ of final good (good 2 ). The production technologies of the agents are Leontief and one-to-one, and we denote $q=q_{1}=q_{2}$.

Each production unit $A_{i}, i \in\{1,2\}$, has private information on its constant marginal $\operatorname{cost} \theta_{i}$. These marginal costs are drawn independently from the same common-knowledge distribution with discrete support $\Theta=\{\underline{\theta}, \bar{\theta}\}$, where we denote by $\Delta \theta=\bar{\theta}-\underline{\theta}>0$ the spread of uncertainty. With probability $\bar{\nu}$ (respectively, $1-\nu$ ), an agent is efficient (respectively, inefficient) and has a cost $\underline{\theta}$ (respectively, $\bar{\theta}$ ).

The principal maximizes the revenue from selling the final good minus the monetary transfers to the agents, namely

$$
W=S(q)-\left(t_{1}+t_{2}\right)
$$

where $S^{\prime}(\cdot)>0$ and $S^{\prime \prime}(\cdot)<0$ and $S^{\prime \prime \prime}(\cdot) \geq 0 . .^{7}$

Each production unit maximizes its own profit:

$$
U_{i}=t_{i}-\theta_{i} q
$$

- Organizational forms, contracts, and side contracting. Centralization. Under centralization, the principal communicates simultaneously with the two units of the firm. Because he may not be able to prevent lateral communication between the agents, collusion becomes a concern within the organization. ${ }^{8}$ Both agents may agree on a side contract that manipulates their information reports into the grand-mechanism proposed by the principal and promotes their collective goal at the expense of the principal's.

Under centralization and in the absence of any communication limit between the principal and the agents, a general contract $M$, or grand-mechanism, offered by the principal to the producing agents is a triplet $\left\{q\left(\hat{\theta}_{1}, \hat{\theta}_{2}\right) ; t_{1}\left(\hat{\theta}_{1}, \hat{\theta}_{2}\right) ; t_{2}\left(\hat{\theta}_{1}, \hat{\theta}_{2}\right)\right\}$, where $\hat{\theta}_{i}$ is $A_{i}$ 's report on his private information.

Because of the symmetry of the modeI, it is a well-known result that there is no loss of generality in looking for the optimal contract within the class of mechanisms that are symmetric, i.e., such that $t_{1}(\cdot)=t_{2}(\cdot)=t(\cdot)$ when the agents do not collude.

For the sake of simplifying our notations, we focus on the case of a symmetric grand-mechanism: we denote $t(\bar{\theta}, \bar{\theta})=\bar{t} ; t(\underline{\theta}, \bar{\theta})=\hat{t}_{1} ; t(\bar{\theta}, \underline{\theta})=\hat{t}_{2} ; t(\underline{\theta}, \underline{\theta})=t$ and we use a similar notation for $q(\cdot)$. Note that the symmetry and the discreteness of the set

\footnotetext{
1 The latter assumption is only used in footnote 18

${ }^{8}$ It has been noted by sociologists (see, for instance, Coleman (1990, p. 253)) that agents can implement a cooperative norm when there is communication between them.
} 
of types of our model implies also that $q(\cdot)$ depends only on the sum of both types and therefore it is without loss of generality that $\hat{q}_{1}=\hat{q}_{2}=\hat{q}$.

We envision a side contract between the input suppliers as first, a manipulation of report function, and second, a set of ex post budget-balanced transfers between the agents. This side contract is therefore a triplet $S C=\left\{\phi\left(\hat{\theta}_{1}, \hat{\theta}_{2}\right) ; y_{1}\left(\hat{\theta}_{1}, \hat{\theta}_{2}\right) ; y_{2}\left(\hat{\theta}_{1}, \hat{\theta}_{2}\right)\right\}$, with the ex post budget-balance constraint $\sum_{i=1,2} y_{i}\left(\theta_{1}, \theta_{2}\right)=0$, for all $\theta_{1}, \theta_{2}$. This triplet is contingent on the agents' reports of their individual information to a third party or side-contract mechanism designer.

Using a third party as a side-contract mechanism designer simplifies the problem of coalition formation under asymmetric information and helps to characterize precisely the set of collusion-proof grand-mechanisms in a tractable way. ${ }^{9}$ Side contracts are assumed to be enforceable by the third party. However, in several of our interpretations of the model, we stress that these side contracts are only reduced forms for the underlying repeated relationships that enforce these norms of reciprocal exchanges of favors. ${ }^{10}$

Under centralization, the third party is benevolent and maximizes the sum of the expected profits of both agents. Hence, both colluding parties are given the same bargaining power at the coalition-formation stage. This assumption captures the idea that both agents are given very similar levels of authority in the organization and are located at the same level of the hierarchy tree. Keeping an equal bargaining power between the two colluding partners fits well with the sociological literature on the development of norms of reciprocity within what Dalton (1959) describes as a "horizontal clique." Moreover, remaining with the interpretation that side contracts are self-enforceable, the centralized organization aims at modelling a situation in which both agents are longterm players. For instance, they are the unique suppliers of essential inputs because there does not exist any market for those imputs. Alternatively, they may both have invested in a specific know-how or in developing technological skills that make both of them indispensable to the firm. This long-term relationship of both agents with the firm allows them to develop equal reputations for collusive behavior.

Moreover, in some cases the third party is not only a modelling short cut but may also correspond to some physical entity like a trade union or industry association, and its benevolent behavior can be derived from the assumption that there exists a competitive fringe of potential leaders for these associations.

Delegation. Under delegation, the firm is instead a three-layer hierarchy. Agent $A_{1}$ contracts with agent $A_{2}$ for the production of the intermediate good and with the principal for the production of the final output. There is no direct communication between $A_{2}$ and $P$. Information must flow up the whole hierarchy before reaching $P$. Consistent with the case of centralization, we assume therefore that communication is costless between the two agents.

Delegation describes a side-contracting environment of its own; contrary to the case of centralization, a side contract needs to be signed in equilibrium before any production occurs. Otherwise, $A_{2}$ does not produce his essential input, and the whole project breaks down.

A grand-mechanism $M$ offered by the principal to $A_{1}$ is a pair $\left\{q\left(\hat{\theta}_{1}, \hat{\theta}_{2}\right) ; 2 t\left(\hat{\theta}_{1}, \hat{\theta}_{2}\right)\right\}$, where $\left(\hat{\theta}_{1}, \hat{\theta}_{2}\right)$ is unit $A_{1}$ 's report on all the information he has learned during the process

${ }^{9}$ Laffont and Martimort (1997a) explain more extensively this modelling choice. It avoids the difficult signalling issues that arise when an informed party makes the side-contract offer (see Maskin and Tirole, 1992). Moreover, using a third party as an external coordinating device gives the best chance to the coalition and provides a characterization of the lowest bound of what can be achieved by the principal.

${ }^{10}$ For further discussions on the enforceability of side contracts, we refer to Tirole (1992) and Martimort (1996) and (1997), who provide explicit modellings of the emergence of these self-enforcing norms of reciprocal behavior in various repeated-game contexts. 
of side contracting with $A_{2}$. For ease of comparison with the case of centralization, we denote by $2 t$ the transfer received by $A_{1}$ from the principal.

For a given grand-mechanism, a side contract $S C$ is a pair corresponding to a manipulation of the global report made by $A_{1}$ to the principal and a side transfer from $A_{1}$ to $A_{2}$. Formally, we have $S C=\left\{\phi\left(\theta_{1}, \hat{\theta}_{2}\right) ; y_{2}\left(\theta_{1}, \hat{\theta}_{2}\right)\right\}$, where $\theta_{1}$ is the middle-principal $A_{1}$ 's type and $\hat{\theta}_{2}$ is agent $A_{2}$ 's report on his private information to $A_{1}$. ${ }^{\text {. }}$

There are two noticeable differences with the case of centralization. First, the principal does not give any direct transfer, nor does he communicate directly with agent $A_{2}$ at the bottom of the hierarchy. The right to contract for the supply of the intermediate product is instead relinquished to the intermediate agent. This situation describes therefore an organization where the agents have different levels of authority and where asymmetry between them is the rule. Second, we assume that the underlying physicals (asset specificity, market environment, and so forth) behind this asymmetry require all the bargaining power at the side-contracting stage to be given to one particular agent, say $A_{1}$.

This asymmetric design of the organization and its consequences for the distribution of bargaining power within the firm are quite natural assumptions to make in a number of contexts. For instance, it may be that $A_{2}$ can easily be replaced because there is a well-established competitive market supplying the intermediate input. Hence, $A_{1}$ can deliver the final product even if $A_{2}$ does not accept the side contract offered. Instead, $A_{1}$ has developed some know-how or technological skills that are firm-specific and cannot be replicated by other suppliers of the final input. ${ }^{12}$ Sticking to the underlying repeated-game motivation for the collusion game, $A_{1}$ can be viewed as a longterm player entrenched in the firm who is facing a sequence of short-term players $A_{2}$. Following the logic of the reputation literature, $A_{\mathrm{I}}$ should be able to gain all bargaining power at the side-contracting stage. ${ }^{13}$

The comparison between delegation and centralization that we are going to carry out is thus an exercise in comparative organizations in which we take as given the set of underlying physicals discussed above.

Timing of the side-contracting games. The timing of the game under centralization is the following:

1. Nature draws the value of each agent's cost $\theta_{i}$, for $i \in\{1,2\}$. Each of these agents learns only his own type.

2. The principal $P$ proposes the grand-mechanism $M$.

3c. Each agent accepts or refuses this grand-contract. If he refuses, he gets a reservation utility normalized at zero.

4c. If both agents accept the grand-contract, the third party offers the side contract $S C$ to the agents.

${ }^{11}$ Equivalently, in an indirect-mechanism version of the game, $A_{1}$ contracts on the amount $q_{2}$ produced by $A_{2}$ for a given level $q_{1}$ of final output contracted by $P$, i.e., he offers a nonlinear transfer price $y_{2}\left(q_{2}, q_{1}\right)$ to the agent. Because the technology exhibits perfect complementarity, necessarily $q_{2}=q_{1}$ for such a nonlinear price.

12 In particular, as has been discussed in Eccles (1985), under market agency, $A_{1}$ 's rights of control include not only the specification of the transfer price for internal transactions but also the decision to supply the intermediate good internally or not.

${ }^{13}$ See, for instance, Fudenberg and Levine (1989), who argue that a long-term player can achieve his Stackelberg payoff when he plays repeatedly in front of short-term players when the Iatcer are slightly uninformed on the long-term player's type. 
5c. Each agent accepts or refuses this side contract. If at least one agent refuses, the grand-contract is played noncooperatively. In this case, reports are made directly in the grand-mechanism and the next two stages of the game do not occur.

6c. If the side contract has been accepted, reports in the side contract take place. Each agent reports noncooperatively his type to the third party.

7c. The corresponding side transfers and the reports in the grand-mechanism requested by the manipulation function are made.

8. The quantity of output and the monetary transfers requested by the grand-mechanism $M$ are enforced.

The side-contracting agreement between the agents occurs after the acceptance of the grand-contract. This agreement can be viewed as a short cut capturing how the norm of reciprocity is established between the input suppliers in their manipulation of accounts. This norm can be enforced through a repeated relationship that can only take place once the firm's boundaries have been established. The design of the firm boundaries also creates the scope for the bilateral communication between the agents that is at the origin of their collusive behavior. Hence, agreement to work for the firm has to be made before the enforcement of any collective manipulation of reports. ${ }^{14}$

Under delegation, the timing of the game follows a similar sequence:

1. Nature draws the value of each agent's cost $\theta_{i}$, for $i \in\{1,2\}$. Each of these agents learns only his own type.

2. The principal $P$ proposes the grand-mechanism $M$ to $A_{1}$.

3d. $A_{1}$ accepts or refuses this contract. If he refuses, the game ends and both agents receive their reservation utility normalized to zero.

4d. If he has accepted the grand-mechanism, $A_{1}$ offers a side contract SC to $A_{2}$.

5d. $A_{2}$ accepts or refuses this side contract. If he refuses, the game ends and both $A_{1}$ and $A_{2}$ get their reservation utility.

6d. If the side contract has been accepted, $A_{2}$ reports to $A_{1}$.

7d. $A_{1}$ reports to $P$ the aggregated information he has learned according to the manipulation function specified in the side contract.

8. The quantity of output and the monetary transfers requested by the composition of the grand-mechanism $M$ and the side contract $S C$ are enforced.

The first difference between this timing and that under centralization comes from the fact that all bargaining power is now given to one agent in the side contracting. Note also that, as under centralization, the acceptance decision of the bottom-level agent is necessary for any production to occur ${ }^{15}$ and the acceptance decision of the intermediate principal is made before any further side contracting.

The second difference is that the acceptance decision of the bottom agent under delegation takes place at the side-contracting stage after the learning of the intermediate agent's type, i.e., with more information. This second difference can only be detrimental to the principal but will turn out to be irrelevant.

' Alternatively, there may exist higher transaction costs of side contracting for agents who meet on a less regular basis outside the firm than if they meet more regularly inside the firm.

${ }^{\text {ts }}$ This assumption could be relaxed by allowing the intermediate principal to have at his disposal an alternative, much less efficient external supply of the intermediate good. As we stressed earlier on, such an extension of our basic model would also justify our assumption on the asymmetric allocation of bargaining power at the side-contracting stage. 


\section{No limit on communication between the principal and the agents}

Centralization: the second-best outcome is collusion-proof. First, we note that in our context the optimal contract without side contracting between the agents can be equivalently implemented in Bayesian and in dominant strategies since it corresponds to a strictly decreasing schedule of outputs (see Proposition 1 below for a derivation of those outputs). ${ }^{16}$ For this optimal contract, which can be taken to be symmetric without loss of generality, the following dominant strategy incentive constraints of an efficient agent are binding:

$$
\begin{aligned}
& \underline{t}-\underline{\theta} \underline{q} \geq \hat{t}_{2}-\underline{\theta} \hat{q} \\
& \hat{t}_{1}-\underline{\theta} \hat{q} \geq \bar{t}-\underline{\theta} \bar{q} .
\end{aligned}
$$

There is still some leeway in writing the participation constraint of an inefficient agent. Since in a Bayesian setting this constraint is binding for the optimal contract, only the expectation of the payment received by the inefficient agent is in fact determined:

$$
\nu\left(\hat{t}_{2}-\bar{\theta} \hat{q}\right)+(1-\nu)(\bar{t}-\bar{\theta} \bar{q})=0
$$

The principal thus has some freedom in choosing both $\hat{t}_{2}$ and $\bar{t}$ as long as (3), (4), and (5) are all binding. One possibility consists in offering to the inefficient agent a pair of transfers so that he is willing to participate in all states of nature. In this case, the following ex post participation constraints are binding:

$$
\begin{aligned}
& \hat{t}_{2}-\bar{\theta} \hat{q} \geq 0, \\
& \bar{t}-\bar{\theta} \bar{q} \geq 0 .
\end{aligned}
$$

Optimizing the principal's profit when (3), (4), (6), and (7) are all binding gives us the characterization of the second-best outcome without side contracting.

Strikingly, the simple symmetric mechanism proposed above turns out to be robust to the manipulations of reports by the coalition made by the two agents. To show why collective deviations do not matter, let us assume for the moment that agents know each other's costs when they make their collusive agreement. In this case, a collusionproof contract has to ensure that each possible coalition prefers to jointly tell the truth to the principal rather than lie. It must be a strong Nash equilibrium for the agents to reveal their joint information when they collude under symmetric information: ${ }^{17}$

$$
\begin{aligned}
2 \underline{t}-2 \underline{\theta} \underline{q} & \geq \hat{t}_{2}+\hat{t}_{1}-2 \underline{\theta} \hat{q} \\
\hat{t}_{1}+\hat{t}_{2}-(\underline{\theta}+\bar{\theta}) \hat{q} & \geq 2 \bar{t}-(\underline{\theta}+\bar{\theta}) \bar{q} .
\end{aligned}
$$

We test in turn the incentives of each coalition to form and to manipulate its joint

\footnotetext{
${ }^{16}$ See Mookherjee and Reichelstein (1992) for a formal proof of this result.

${ }^{17}$ We do not mention the upward incentive constraint where two efficient agents claim that they are inefficient, namely, $2 \underline{t}-2 \underline{\theta q} \geq 2 \bar{t}-2 \theta \bar{q}$. It is implied by (8) and (9) and by the monotonicity condition $\bar{q}<\hat{q}$.
} 
reports to the principal. ${ }^{18}$ Consider first a coalition made of two inefficient agents. Since both of these agents get an individual payoff equal to zero irrespective of the other agent's report, they have no reason to manipulate their joint reports. Stakes of collusion between two inefficient agents do not exist. Similarly, a coalition made of an efficient agent and an inefficient one has no incentive to collectively misrepresent. The inefficient agent still has a payoff of zero independently of the efficient one's report. On the other hand, the efficient agent does not gain from making a coalition with the inefficient one, since when (6) and (7) are binding, the binding dominant incentive constraint (4) takes exactly the same form as (9). There is no scope for a collusive exchange between the efficient and the inefficient agent when they may receive different transfers $\hat{t}_{1}$ and $\hat{t}_{2}$. Finally, consider a coalition made of two efficient agents and suppose they jointly report that they have different types. If (3), (4), (6), and (7) are binding, (8) amounts to checking that $\hat{q} \geq \vec{q}$, a monotonicity condition satisfied by the second-best schedule of outputs.

With no restriction on the set of available contracts, collusion does not impede the efficient allocation of resources in the centralized organization, since (8) and (9) are satisfied at no further cost to the principal when (3), (4), (6), and (7) are binding. The implementation of the second-best outcome is still ensured when coalition formation takes place under symmetric information. Asymmetric information at the coalition formation stage does not change anything in the writing of the collusion-proof constraints. ${ }^{19}$ The scope for collusion disappears when the principal offers transfers as described above. Hence, we can summarize the discussion so far as follows.

Proposition 1. The optimal centralized arrangement with no limit on communication entails

(i) The same levels of output as in the absence of side contracting between the agents. This strictly decreasing schedule of outputs, $q_{0}^{C}>\hat{q}_{0}^{C}>\bar{q}_{0}^{C}$, is given by

$$
\begin{aligned}
& S^{\prime}(\underline{q} \delta)=2 \underline{\theta} \\
& S^{\prime}\left(\hat{q}_{\tilde{\sigma}}^{C}\right)=\underline{\theta}+\bar{\theta}+\frac{\nu}{1-\nu} \Delta \theta \\
& S^{\prime}\left(\bar{q}_{\tilde{\sigma}}^{\complement}\right)=2 \bar{\theta}+\frac{2 \nu}{1-\nu} \Delta \theta .
\end{aligned}
$$

(ii) The same informational rent for each type of agent as in the absence of side contracting: For an efficient agent,

$$
\underline{U}_{0}^{C}=\Delta \theta\left(\nu \hat{q}_{0}^{C}+(1-\nu) \bar{q}_{0}^{C}\right)
$$

for an inefficient agent,

$$
\bar{U}_{0}^{C}=0
$$

18 We only mention here the downward coalition incentive constraints. However, in the second-best outcome, the transfer $t$ given to an efficient agent may be very high. Then it is not clear whether the downward coalition incentive constraint $\hat{t}_{1}+\hat{t}_{2}-(\underline{\theta}+\bar{\theta}) \hat{q} \geq 2 \underline{t}-(\underline{\theta}+\bar{\theta}) q$ is satisfied or not. For dominant incentive constraint transfers, this condition holds strictly when $q+\bar{q}>\overline{2} \hat{q}$. which is guaranteed for the second-best schedule of outputs when $S^{t \prime \prime} \geq 0$ (Laffont and Martimont, 1997a). Laffont and Martimort (1997b) show that the second-best outcome under centralization can always be achieved as a weak collusion-proof outcome with Bayesian incentive compatibility, but the strong collusion-proofness of the allocation is not satisfied.

${ }^{19}$ See Laffont and Martimort (1997a) for the proof that collusion-proofness constraints take the same form under asymmetric information. Only participation constraints differ. 
Proof. The proof follows directly from the discussion above. Optimal levels of output when agents do not cooperate are obtained with standard techniques. The levels of rents are then derived from using (3), (4), (6), and (7) when binding. Q.E.D.

Hence, with no limit on communication, i.e., when the principal has the ability to offer complete contracts contingent on the whole vector of reports for both agents, collusion has no bite on the efficiency of the organization in our setting. ${ }^{20,21}$ The principal has a sufficiently large set of instruments to introduce some asymmetry between the agents even in a centralized organization when the bargaining powers of the potentially colluding agents are identical. They receive different transfers in the state of nature where their types are different.

Indeed, using that (6) (respectively, (7)) is binding, we find that $\hat{t}_{2}-\underline{\theta} \hat{q}=\Delta \theta \hat{q}$ (respectively $\hat{t}_{\mathrm{l}}-\underline{\theta} \hat{q}=\Delta \theta \bar{q}$ ). The transfer received by an inefficient agent when he is facing an efficient one is relatively high to cover his cost of producing a large output. Comparatively, the transfer received by an efficient agent when he is facing an inefficient one is relatively low because he has a lower cost of production and $\hat{t}_{2}>\hat{t}_{1}$.

This discrepancy in the treatments received by the two different agents breaks their common interest in collectively manipulating the reports they make to the principal. They have no more incentives to collude against him, and collusion-proofness is achieved at no cost for the organization. More precisely, the richness of the set of transfers is helpful to ensure that ex post participation constraints and coalition incentive constraints do not conflict.

- Delegation: a particular implementation of the second-best outcome. Under delegation, the informed middle principal $A_{1}$ offers a contract to $A_{2}$. We know from Maskin and Tirole (1990) that with private values and quasi-linear utility functions, the outcome of this informed principal contracting game is the same as if $A_{2}$ were informed on $A_{1}$ 's type. In the Appendix, we briefly sketch the complete analysis of this delegation game.

Proposition 2. With no limits on communication, the optimal mechanism under delegation implements the second-best outcome.

Proof. See the Appendix.

The delegation game corresponds in fact to a particular implementation of the centralized outcome. Under delegation, the relationship between $A_{1}$ and $A_{2}$ looks very much like the relationship between $P$ and any of his agents in the case of centralization. The fact that $A_{2}$ 's acceptance decision is made under complete information on $A_{1}$ 's cost does not create any further loss, as ex post individual rationality and dominant strategy implementation for one agent can be achieved from a Bayesian implementation without any loss in this two-agent context.

The inefficient agent $A_{2}$ at the bottom of the hierarchy gets a zero rent whatever $A_{1}$ 's type, since the Iatter always designs the transfer price for the intermediate output in such a way that it minimizes $A_{2}$ 's informational rent. Hence, for the agent at the bottom of the hierarchy, the setting is similar to that under centralization discussed in

${ }^{20}$ If the number of types increases, the number of coalition incentive constraints increases sharply and the implementation of the second-best outcome with collusion-proofness and dominant strategy constraints (imposed to ensure strong collusion-proofness) is not feasible. Laffont and Maskin (1980) proved that only pooling decision rules can be implemented when types are continuously distributed.

${ }^{21}$ Focusing on a two-type model and specifying limits on comununication helps us to show what are the nexi and the stakes of collusion in a simpler manner (see Section 4). An alternative route discussed in Section 6 is to look at more complex information structures with correlated information and to give up dominant strategy implementation. 
the previous subsection, the only difference being that now he receives an incentive contract from the intermediate agent rather than directly from the principal. The final outcome is the same as under centralization for this agent, who receives a zero interim expected utility when he is inefficient. To induce instead an efficient agent $A_{2}$ to reveal his type, $A_{1}$ must bear some agency cost, i.e., he must pay some informational rent to $A_{2}$ that takes exactly the same form as under centralization. This agency cost would have been directly borne by the principal if centralization had been chosen instead. $A_{1}$ 's payoff is therefore different depending on whether or not $A_{2}$ claims he is inefficient.

The fact that $A_{1}$ has borne some agency costs is nevertheless not costly for the hierarchy's efficiency. In fact, in designing the compensation of the intermediate agent, the principal takes into account that $A_{L}$ has borne these agency costs and offers different transfers to $A_{1}$ depending not only on his own type but also on the information he has learned from $A_{2}$. This fact can easily be seen in the extreme case where $A_{1}$ does not have any private information of his own and is made residual claimant for the profit of the firm by a simple fixed fee offered by the top principal. Instead of paying directly the agency cost for learning that $A_{2}$ is efficient, the principal makes $A_{1}$ learn this information and rewards him for this learning with an upfront fee. The agency cost remains the same but is paid in an indirect way under delegation. Finally, $A_{1}$ 's private incentives to extract $A_{2}$ 's information can be perfectly aligned with those of the top principal, since they share the same amount of asymmetric information vis-à-vis $A_{2}$, i.e., as long as only the interim participation constraints of $A_{1}$ have to be ensured. ${ }^{22}$ Adding private information for the middle principal does not change this result, as has already been proved in different contexts by Melumad, Mookherjee, and Reichelstein (1995), Baron and Besanko (1992) and Gilbert and Riordan (1995).

Theorem 1. With no limits on communication, centralization and delegation perform equally well.

\section{Limits on communication between the principal and the agents}

- Limits on communication are pervasive in large organizations. Different modelling devices are available for representing these communication constraints. For instance, Melumad, Mookherjee, and Reichelstein (1992) model the incompleteness of communication as the possibility for the agents to report only a finite number of messages on their types even if these types are continuously distributed. Communication constraints impose that the whole vector of information relevant for decision making cannot be transmitted or received by the principal. Alternatively, one can model the processing of each signal reported as involving a fixed $\operatorname{cost}^{23}$ and then compare different communication channels with respect to the overall fixed costs they involve. Finally, one can also model inefficiencies in information processing by assuming that the principal only receives imperfect signals. ${ }^{24}$

In the absence of a more fundamental theory of information costs that could be operational in incentive theory and could explain the origins of the costs of writing some contractual contingencies, we choose to follow this last path. In our model, only rough statistics can be used as an argument of the principal's grand-mechanism. We assume that the whole vector of types cannot be transmitted to the principal and that

\footnotetext{
${ }^{22}$ The same intuition also holds in the more complicated multilayer hierarchies analyzed by Crémer and Riordan (1987).

${ }^{23}$ This fixed cost may be the cost of writing contracts contingent on these signals, as in Dye (1985).

${ }^{24}$ Green and Laffont (1982) put constraints on the dimensionality of the messages that cand be transmitted, while Green and Laffont (1986) use Shannon's information theory to model these constraints.
} 
the identity of the senders remains unknown to him. Instead, only the sum of the reports made by the agents can be sent and is known at the top of the hierarchy.

Our motivation for focusing on limits on communication between the principal and the agents is that the information channels between the production stages and the headquarters are more likely to be prone to information loss. For instance, the organization of the firm could be such that the principal cannot receive information from the agents directly, but only through an intermediate supervisor who is benevolent but unable to transmit to the principal the exact components of the total cost of production he receives from the agents. Moreover, limits on communication prevent the principal from enforcing asymmetric compensations between the agents and they receive transfers that depend only on the aggregate type. Such an intermediate level is likely to emerge in large organizations when the principal has a limited ability to treat all the information flowing up the organization for standard reasons of bounded rationality.

When the transfer given by the principal to any agent is dependent only on the sum of their reports on both $\theta_{1}$ and $\theta_{2}$ and not on the exact realizations of these reports and the identity of the senders, a symmetric contract under centralization must satisfy an anonymity condition. It is of the form $\{(t, q) ;(\hat{t}, \hat{q}) ;(\bar{t}, \bar{q})\}$, with the same transfer being given to both agents in each state of nature. Under delegation, the principal is now offering such a triplet $\{(2 \underline{t}, \underline{q}) ;(2 \hat{t}, \hat{q}) ;(2 \bar{t}, \bar{q})\}$, but to $A_{1}$ only.

Alternatively, anonymity can be interpreted in terms of nonverifiability. Indeed, it amounts to assuming that only production, not the relative efficiency, of the agents is verifiable (Hart and Moore, 1988). This interpretation of the model is nevertheless problematic if we assume also that the agents' production and relative efficiency are in fact verifiable and can be written in a side contract enforced by the court. Alternatively and more convincingly, we can still assume the nonverifiability of the relative efficiency if we keep the interpretation that these side contracts are made self-enforceable through the repeated relationship between the agents. Both the assumption of limited communication and that of nonverifiability of the relative efficiency amount to assuming a greater contractual ability of the agents between themselves than with the principal. Keeping the repeated-game motivation for their collusion, this is also assuming that the principal has a much shorter relationship with the agents within the firm than the agents have between themselves.

$\square$ Centralization. The optimal anonymous contract without side contracting. Requiring anonymity of the transfers does not affect the efficiency of the centralized organization in the absence of side contracting. With limits on communication, the second-best outcome can still be achieved with dominant strategies and interim participation constraints. The set of transfers is still rich enough to ensure that (3), (4) (written with $\hat{t}_{1}=\hat{t}_{2}=\hat{t}$ ), and (5) are all binding. The second-best schedule of output remains implementable at the second-best cost.

Proposition 3. With limits on communication and without side contracting, the optimal anonymous contract under centralization still achieves the second-best outcome.

Because the participation constraint of an inefficient agent is written in expectation, there are still some degrees of freedom in specifying state-by-state transfers to satisfy this constraint. One degree of freedom is used to satisfy the dominant strategy requirement. The second degree of freedom is used to cope with the limits on communication constraint. A centralized organization does as well with or without a limit on communication as long as the agents do not engage in side contracting. When collusion is not an issue, limits on communication do not matter.

The stake of collusion. However, our assumption of limited communication creates some scope for collusive behavior. To see why, we return to the optimal symmetric 
mechanism under no collusion discussed above. For this mechanism, (4) is binding and the anonymity condition $\hat{t}_{\mathrm{l}}=\hat{t}_{2}=\hat{t}$ holds. Since the headquarters implements a strictly decreasing schedule of output $\hat{q}>\bar{q}$, we observe that

$$
\bar{t}-\bar{\theta} \bar{q}>\hat{t}-\bar{\theta} \hat{q}
$$

Therefore, the truthful revelation of his type by an efficient agent, say $A_{1}$, exerts a negative externality on the inefficient agent $A_{2}$. The same thing holds for all separating allocations of outputs $(\hat{q}>\vec{q})$ that can be proposed to the units. The transfer received by a high-cost agent is higher if the other input supplier is claiming he has also a high cost.

By bribing this efficient agent so that he misreports his type to the principal, $A_{1}$ can strictly gain from collusion and can get a positive profit. As long as this bribe ensures participation to the collusive agreement and incentive compatibility at the coalition formation stage, the gain $\bar{t}-\bar{\theta} \bar{q}-(\hat{t}-\bar{\theta} \hat{q})=\Delta \theta(\hat{q}-\bar{q})$ can be shared between the agents. Note that this gain is positive if the principal wants to implement a strictly decreasing schedule of outputs. In particular, for a mechanism implementing an output allocation with partial pooling such that $\hat{q}=\bar{q}$, this gain is equal to zero. Collusion between the two units is useless. Again, the intuition here is that such a partial-pooling contract makes the inefficient agent $A_{2}$ indifferent between the reports made by $A_{1}$ and thus destroys any externality coming from the truthful strategy of an efficient agent $A_{1}$. The scope for collusion exists only when the allocation of output is responsive to the units' information.

The optimal symmetric contract with side contracting. We solve the game backward to describe the set of collusion-proof grand-mechanisms such that collusion does not arise along the equilibrium path. To be accepted along the equilibrium path, the side contract must be Bayesian incentive compatible and individually rational. The first requirement says that it is a best strategy for the agent to reveal his type in the coalition formation stage. The last requirement ensures that the agent accepts the side contract when he gets a higher utility than in the absence of a cooperative agreement. ${ }^{25}$

We have already noted that a partial pooling between $\hat{q}$ and $\bar{q}$ destroys the stake of collusion under either symmetric or asymmetric information between the agents. Another way to destroy this stake is to raise the transfer $\hat{t}$ given to an efficient agent. This makes it harder for an inefficient agent to bribe $A_{1}$ for misreporting. In fact, the transfer $\hat{t}$ has to be raised until the following coalition incentive constraint is satisfied:

$$
2 \hat{t}-(\underline{\theta}+\bar{\theta}) \hat{q} \geq 2 \bar{t}-(\underline{\theta}+\bar{\theta}) \vec{q} .
$$

This constraint tells us that an efficient agent and an inefficient one do not make profit from jointly misreporting that they are both inefficient.

Finally, the optimal anonymous contract solves the following program (hereafter denoted $(C)):^{26}$

${ }^{25}$ The difficulty is to specify the out-of-equilibrium beliefs following the refusal of one agent to play the side mechanism. There is no loss of generality in looking for weak collusion-proof contracts, such that deviations from the null side contract are not beneficial with out-of-equilibrium passive beliefs (Laffont and Martimort, 1997a).

${ }^{26}$ All the incentive, participation, and coalition constraints that have been omitted in $(C)$ are automatically satisfied at the optimum of this program. 


$$
\max _{M} \nu^{2}(S(q)-2 t)+2 \nu(1-\nu)(S(\hat{q})-2 \hat{t})+(1-\nu)^{2}(S(\bar{q})-2 \bar{t})
$$

subject to

$$
\begin{aligned}
\underline{t}-\underline{\theta} \underline{q} & \geq \hat{t}-\underline{\theta} \hat{q} \\
\nu(\hat{t}-\bar{\theta} \hat{q})+(1-\nu)(\bar{t}-\bar{\theta} \bar{q}) & \geq 0
\end{aligned}
$$

and (14). The participation constraint of an inefficient agent is taken in expectation because of asymmetric information at the time of acceptance of the grand-contract. The first constraint is both an individual incentive constraint for an efficient agent and a coalition incentive constraint for a pair of efficient agents. The next proposition characterizes this optimal anonymous contract with limits on communication and asymmetric information between agents.

Proposition 4. With limits on communication, the optimal anonymous contract under centralization entails the following:

(i) A strictly decreasing schedule of outputs $\underline{q}^{C}=\underline{q}^{C}>\hat{q}^{C}>\bar{q}^{C}$ given by

$$
\begin{aligned}
& S^{\prime}\left(\hat{q}^{C}\right)=\underline{\theta}+\bar{\theta}+\frac{1+\nu}{2(1-\nu)} \Delta \theta \\
& S^{\prime}\left(\bar{q}^{C}\right)=2 \bar{\theta}+\frac{\nu}{(1-\nu)} \Delta \theta .
\end{aligned}
$$

(ii) For an efficient agent, the informational rent with side contracting is

$$
\underline{U}^{c}=\Delta \theta\left(\nu \hat{q}^{c}+(1-\nu) \bar{q} c\right)+\frac{1-\nu}{2} \Delta \theta\left(\hat{q}^{C}-\bar{q}^{c}\right)
$$

for an inefficient agent, it is

$$
\widetilde{U}^{C}=\mathbf{0} \text {. }
$$

Proof. It is obtained simply by inserting the expressions of the transfers when all the constraints in $(C)$ are binding and then optimizing with respect to $(\underline{q}, \hat{q}, \bar{q}) .{ }^{27}$

With respect to the second-best outcome, outputs are distorted in the sense of reducing the stake of collusion $\Delta \theta(\hat{q}-\bar{q})$. We have both $\hat{q}^{C}<\hat{q}_{\delta}^{C}$ and $\bar{q}^{C}>\bar{q}_{\delta}^{C}$. To limit the collective incentives of the input suppliers to both pretend to be inefficient, the headquarters reduces the difference between the output targets he proposes. There is a move toward flatter profiles of outputs that are less responsive to the units' messages. Less flexible rules are implemented when collusion matters. Limits on communication indirectly create reasons for limiting somewhat the use of the agents' messages because, otherwise, one creates scope for their collective manipulation.

With limits on communication, the principal cannot use any more different transfers $\hat{t}_{2}$ and $\hat{t}_{1}$ to create a discrepancy between the agents so that their incentives to collude vanish. The only valuable instrument to play with is the allocation of outputs that are moved in the direction of reducing collusion stakes.

${ }^{27}$ This optimal contract is implemented in dominant strategy. Thus, the best side contract that can be offered by the third party does not depend on out-of-equilibrium beliefs and is strongly collusioh-proof. 
Delegation. Using Lemma A1 in the Appendix and taking now into account our contractual limitation, the collusion-proofness constraints inducing an agent $A_{1}$ to reveal his information can be written as ${ }^{28}$

$$
\begin{gathered}
2 \underline{t}-2 \underline{\theta} \underline{q} \geq 2 \hat{t}-2 \underline{\theta} \hat{q}, \\
2 \hat{t}-\left(\underline{\theta}+\bar{\theta}+\frac{\nu}{1-\nu} \Delta \theta\right) \hat{q} \geq 2 \bar{t}-\left(\underline{\theta}+\bar{\theta}+\frac{\nu}{1-\nu} \Delta \theta\right) \bar{q} .
\end{gathered}
$$

The principal's problem (denoted (D)) then becomes

$$
\max _{M} \nu^{2}(S(q)-2 \underline{t})+2 \nu(1-\nu)(S(\hat{q})-2 \hat{t})+(1-\nu)^{2}(S(\bar{q})-2 \bar{t}),
$$

subject to $(17),(18)$, and

$$
\nu(2 \hat{\imath}-(\underline{\theta}+\bar{\theta}) \hat{q}-\Delta \theta \bar{q})+(1-\nu)(2 \bar{t}-2 \bar{\theta} \bar{q}) \geq 0 .
$$

Inducing revelation from a coalition with two efficient agents is as costly under centralization as it is under delegation. Comparing (14) and (18), we nevertheless note that inducing revelation from a coalition with one efficient and one inefficient agent is more costly under delegation than under centralization. The difference comes from the fact that now $A_{1}$ has to induce $A_{2}$ to reveal his own information. To do this, he would like to distort the manipulation of reports function in a way calling for less output and therefore less informational rent for an efficient agent $A_{2}$. In state $(\underline{\theta}, \bar{\theta}), A_{1}$ thus has more incentives to choose low levels of production to reduce his internal informational problem with $A_{2}$. From the principal's point of view, a pair of agents $(\underline{\theta}, \bar{\theta})$ have strong incentives to collectively reveal that they are $(\bar{\theta}, \bar{\theta})$. A grand-contract discriminating between these two coalitions requires increasing the transfer $\hat{t}$ given to $A_{\mathrm{I}}$ when he reports that the sum of the agents' costs is intermediate. Indeed, to obtain truthful revelation by $A_{1}, P$ not only has to give him a marginal informational rent corresponding to the revelation of his own information but also to reimburse him for the agency cost he has borne in his side contract to learn the value of $A_{2}$ 's information. Obviously, whether obtaining information from a coalition with one efficient and one inefficient agent is in fact more costly than under centralization depends on the value of the transfer $2 \bar{t}$, which itself depends on the participation constraint of the $\bar{\theta}$ agent $A_{1}$.

The participation constraint of a $\bar{\theta}$ agent $A_{1}$ is weaker than under centralization because he benefits from extracting some rent from a $\underline{\theta}$ agent $A_{2}$. Actually, it can be rewritten

$$
\nu(\hat{t}-\bar{\theta} \hat{q})+(1-\nu)(\bar{t}-\bar{\theta} \bar{q}) \geq-\frac{1}{2} \nu \Delta \theta(\hat{q}-\bar{q})
$$

The combination of this weaker participation constraint and the stronger coalition incentive constraint (18) turns out to allow reaching the second best. Indeed, optimizing $(D)$, we find

Proposition 5. With limits on communication, delegation still implements the secondbest outcome.

${ }^{28}$ We write here only the relevant binding upward coalition incentive constraints. 
Proof. All constraints in $(D)$ are binding at the optimum. Replacing transfers by their values and optimizing yields the result.

Coming back to the reasoning in Section 3, the limit on communication does not prevent $A_{k}$, whatever his type, from extracting the inefficient agent $A_{2}$ 's informational rent. Indeed, delegation allows enough flexibility to still satisfy the ex post participation constraints of the agent at the bottom of the hierarchy. Moreover, since under the optimal delegation contract described in Section 3, the productions $q(\bar{\theta}, \theta)$ and $q(\theta, \bar{\theta})$ are equal, there is no loss of generality for the principal in offering transfers to $A_{1}$ such that $2 \hat{t}_{1}=2 \hat{t}_{2}$. Hence, the principal can align $A_{1}$ 's incentives to extract $A_{2}$ 's information with his own by using a set of anonymous transfers.

Because the participation constraint of an intermediate principal can be taken in expectation, his payoff in each state of nature can be adjusted so that he has the right incentives to extract $\boldsymbol{A}_{2}$ 's information and this has no further cost for the principal. The cost of getting information from a coalition with an efficient and an inefficient agent is in fact the same as under centralization without side contracting and the same as under centralization with side contracting but without a limit on communication.

- Comparative analysis. As discussed above, the limit on communication introduces a tension between the coalition and the participation constraints under centralization. This tension is eliminated under delegation. Even if coalition incentive constraints are hardened under delegation, it is easier to induce the agents' participation sequentially. The conflict between participation and coalition incentive constraints is solved.

Theorem 2. With limits on communication, delegation always strictly dominates centralization.

Delegation introduces a conflict between the two agents who can no longer collude in a way that extracts as much from the principal as what they can get under centralization.

More technically, if we make in $(D)$ the change of variable

$$
\overline{\bar{l}}=\bar{t}+\frac{1}{2} \frac{y}{1-\nu} \Delta \theta(\hat{q}-\bar{q})
$$

the constraints of the centralization and delegation cases are identical and the objective function under delegation is larger by an amount $(1-\nu) \nu \Delta \theta(\hat{q}-\bar{q})$.

Everything happens as if the principal were able to tax the formation of the coalition in a hierarchical structure. Instead of giving $\overline{\bar{t}}$ when both reports are $\bar{\theta}$, he is in fact giving a lower transfer $\bar{t}$. Delegation yields some extra benefit from this implicit tax. Moreover, as shown in the above expression, this implicit tax is precisely equal to the expected value of the stake of collusion that must be distributed to the agents under centralization.

This result can be viewed as a formalization of Wintrobe and Breton's (1986) insight that horizontal cliques affect the firm's efficiency much more than vertical cliques do.

\section{Alternative assumptions}

In this section we discuss our previous assumptions and investigate why delegation may continue to dominate under two alternative assumptions on the information available at the coalition formation stage. 
- Justifying anonymity without limits on communication. So far, we have focused on the case where agents are treated anonymously under centralization because of the existence of some limits on communication. Our results also go through in two other settings of some interest.

First, in his empirical treatment of the transfer pricing problem, Eccles (1985) has argued that agents of an organization put some value on the faimess of the contract they receive. "Faimess" is not given any formal meaning in the work of this author. However, it appears empirically that agents in similar positions within the hierarchy of the firm see as unfair the fact that they may receive different rewards based on different exogenous shocks. To quote Eccles (1985, p. 154), "each agent evaluates the faimess of his or her contract partly in terms of how it compares with the contracts held by others." The requirement of anonymity can be seen as an exogenous constraint capturing the fairness of a contract.

Second, agents in the centralized organization may realize that asymmetric compensation schemes put them at a disadvantage, as we discussed in Section 3, since their collusion may have no bite. They may engage in collusive strategies more complex than simply manipulating their joint reports ex post, i.e., after the offering of a grandmechanism by the principal. In particular, the third party can implement a norm of reciprocity such that ex ante, i.e., before the principal offers any grand-mechanism, agents commit to share any asymmetric transfers they may receive in the future. As we show in Laffont and Martimort (1997a), this collusive strategy can be optimal for the agents because it constrains the principal to offer a grand-mechanism that is anonymous and therefore creates a scope for some collusion ex post.

In both cases, delegation can then be a way to escape the limits on communications imposed in the centralized setting. ${ }^{29}$

$\square \quad$ Side contracting on verifiable information under centralization. When agents have access to a technology making their private information verifiable, they may be able to enforce a cooperative agreement in which they commit to share their private information before playing the grand-mechanism offered by the principal. Information is then internally verifiable even though it remains externally unverifiable. Coming back to our repeated-game interpretation justifying the self-enforceability of the contract, the agents' relationship is now modelled in the very long run. They are then able to enforce a strong norm of reciprocity in which exchange of information takes place freely. When there is symmetric information within the coalition, the relevant coalition incentivecompatibility constraint remains the same and is still given by (14). The only difference with our previous analysis of centralized side contracting is that the participation constraints of an inefficient agent now have to be satisfied ex post when information has been communicated in a verifiable way between the agents. This does not change anything without a limit on communication. As we already noted, when participation constraints are satisfied ex post, the stake of collusion disappears with nonanonymous schemes. Instead, things change with limits on communication. More precisely, participation constraints are now

$$
\hat{t}-\bar{\theta} \hat{q} \geq 0
$$

and

$$
\bar{t}-\bar{\theta} \bar{q} \geq 0 \text {. }
$$

${ }^{29}$ In fact, we have proved an even stronger result. Delegation even with communication constraints can improve on centralization. 
Hardening participation constraints exacerbates the conflict between coalition and participation constraints. It also undermines quite significantly the efficiency of the centralized arrangement.

Proposition 6. With limits on communication and verifiable information in the coalition, the optimal symmetric collusion-proof grand-contract under centralization has $\underline{q}^{C V}=\underline{q}_{0}^{C}$ and always entails some partial pooling, $\hat{q}^{C V}=\bar{q}^{C V}=q^{C V}$, such that

$$
S^{\prime}\left(q^{C \nu}\right)=2 \bar{\theta}+\frac{2 \nu^{2}}{(1-\nu)^{2}} \Delta \theta
$$

Proof. See the Appendix. ${ }^{30}$

Satisfying the ex post participation constraints of an inefficient agent requires increasing excessively the transfers he receives. This makes the incentive constraints of an efficient agent very costly. The least costly way to reduce this burden is to impose some pooling in the optimal allocation. Under centralization, a strong norm of collusive behavior between the units nullifies any screening possibility.

Under delegation, $P$ only gives transfers to $A_{L}$, who knows perfectly $A_{2}$ 's cost because this is verifiable information for him. Hence, $A_{1}$ can take $P$ 's transfers and redistribute them to $A_{2}$ to always induce his participation without letting him have any informational rent. The coalition incentive constraints are now given by (18) and (14). Participation constraints for the intermediate principal must be written ex post and are, respectively,

$$
\begin{aligned}
2 \hat{t}-(\underline{\theta}+\bar{\theta}) \hat{q} & \geq 0 \\
2 \bar{t}-2 \bar{\theta} \bar{q} & \geq 0 .
\end{aligned}
$$

These incentive and participation constraints are the same as those of an agent who would have pooled the units' information. The coalition behaves as an 'informational alliance" in the vocabulary coined by Baron and Besanko (1995).

Proposition 7. With limits on communication and verifiable information in the coalition, the optimal contract under delegation has $\underline{q}^{D \psi}=\underline{q}_{0}^{C}$ and always entails a separating allocation, $\hat{q}^{D V}>\bar{q}^{D V}$, such that

$$
\begin{aligned}
& S^{\prime}\left(\hat{q}^{D \nu}\right)=\underline{\theta}+\bar{\theta}+\frac{\nu}{2(1-\nu)} \Delta \theta \\
& S^{t}\left(\bar{q}^{D V}\right)=2 \bar{\theta}+\frac{\nu(2-\nu)}{(1-\nu)^{2}} \Delta \theta .
\end{aligned}
$$

Proof. (17), (14), and (23) are all binding at the optimum of the principal's problem. (22) is strictly satisfied. Inserting transfers into the principal's objective function and optimizing yields (24) and (25). Q.E.D.

Contrary to centralization, delegation always entails an optimal allocation that is separating. Since partially pooling allocations remain feasible under delegation but are suboptimal, delegation dominates centralization.

${ }^{30}$ In a related context, we have shown that collusion-proofness may not be optimal (see Laffont and Martimort, 1996) in the case of verifiable information. 
Theorem 3. With limits on communication and verifiable information, delegation always achieves a strictly higher profit than centralization. ${ }^{31}$

One interesting result shown by Baron and Besanko (1992) and Gilbert and Riordan (1995) for continuous distributions of types is that the contractual outcome under delegation also achieves a higher payoff for the principal than does the outcome under centralization without side contracting discussed in Section $3 .^{32}$ It is easy to check that this result still holds in our case of discrete distributions. Their result rests on the different informational structure of the two cases. Our result presumes the same informational technologies and rests on different side-contracting costs.

Delegation, ex post participation constraints, and loss of control. Suppose now that, under delegation, the middle principal $A_{1}$ only agrees to sign the grand-contract once he has learned the information revealed by the subcontractor $A_{2}$. Still keeping our assumption of limited communication, the principal's problem (denoted $\left(D^{\prime}\right)$ ) then becomes $^{33}$

$$
\max _{M} \nu^{2}(S(\underline{q})-\underline{t})+2 \nu(1-\nu)(S(\hat{q})-\hat{t})+(1-\nu)^{2}(S(\bar{q})-\bar{t})
$$

subject to (17), (18), and

$$
\begin{aligned}
2 \hat{t}-(\underline{\theta}+\bar{\theta}) \hat{q}-\Delta \theta \bar{q} & \geq 0 \\
2 \bar{t}-2 \bar{\theta} \bar{q} & \geq 0 .
\end{aligned}
$$

The last two constraints denote $A_{1}$ 's participation constraints when he is inefficient and has learned (and paid the agency cost for it) respectively that $A_{2}$ is efficient or inefficient. Optimizing $\left(D^{\prime}\right)$, we find

Proposition 8. With limits on communication and ex post participation constraints for the intermediate principal, delegation does not achieve the second-best. There exists a value $\nu^{*}$ in ]0, 1[ such that the optimal grand-contract under delegation entails the following:

(i) For $\nu<\nu^{*}$, a strictly decreasing schedule of outputs, $\underline{q}^{D^{\prime}}=\underline{q}^{c}>\hat{q}^{D^{\prime}}>\bar{q}^{D^{\prime}}$, which is given by

$$
\begin{aligned}
& S^{\prime}\left(\hat{q}^{D^{\prime}}\right)=\underline{\theta}+\bar{\theta}+\frac{\nu(3-2 \nu)}{2(1-\nu)^{2}} \Delta \theta \\
& S^{t}\left(\bar{q}^{D^{\prime}}\right)=2 \bar{\theta}+\frac{\nu(2-\nu)(1-2 \nu)}{(1-\nu)^{3}} \Delta \theta
\end{aligned}
$$

(ii) For $\nu \geq \nu^{*}$, a partial pooling in the allocation of output,

" Note that agent $A_{2}$ loses from the use of verifiable information and can oppose sharing information. This reinforces the domination of delegation.

${ }^{32}$ The intuition for the result is that under centralization and no collusion, each agent has an incentive to overstate his cost to increase the transfer he receives from the principal, and that this extemality is internalized under delegation.

${ }^{31}$ We omit here the participation constraint of an efficient agent $A_{1}$ having learned that $A_{2}$ is also efficient, namely $\underline{t}-2 \underline{\theta} \underline{q}-\Delta \theta \hat{q} \geq 0$. It turns out to be satisfied ex post. 


$$
\underline{q}^{D^{\prime}}=\underline{q}_{0}^{C}>q^{D^{\prime} P}=\hat{q}^{D^{\prime}}=\bar{q}^{D^{\prime}}
$$

where $q^{D P}$ is given by

$$
S^{\prime}\left(q^{D^{\prime} P}\right)=2 \bar{\theta}+\frac{2 \nu^{2}}{(1-\nu)^{2}} \Delta \theta
$$

Proof. See the Appendix.

With this timing of side contracting, the input supplier $A_{1}$ has to make a positive profit whatever the realization of his own cost and whatever he may have learned from $A_{2}$ during the course of side contracting. In particular, he must make a nonnegative ex post profit even if he has to pay some informational rent to $A_{2}$. Imposing this ex post participation constraint undermines the efficiency of the allocation proposed by the principal. Indeed, delegation always achieves a lower level of profit for the organization than does a centralized structure without side contracting. As is well known from standard one principal-one agent models, the requirement of satisfying some ex post participation constraint conflicts with efficiency and introduces allocative distortions.

When an extra layer is added within the hierarchy, the conflict between efficiency and rent extraction is sharply exacerbated. More allocative distortions are required to minimize the burden of informational rent. Note that this loss of control is due not to the fact that the middle principal is privately informed on his cost but to the fact that he is also informed on the type of the subcontractor when accepting the grand-contract. It is this information on the efficiency parameter of the first stage of production that becomes more costly to extract as the length of the hierarchy increases. ${ }^{34}$

The principal can no longer use the fact that the intermediate principal accepts his contract before knowing $A_{2}$ 's type to make him internalize the hierarchy's incentives to extract $A_{2}$ 's information. Introducing this new cost of delegation creates a real tradeoff between the costs of collusion under centralization and the loss of control arising under delegation. To determine the dominance areas of each structure, we note that delegation is dominated by centralization when the former corresponds to an optimal contract involving some pooling. Pooling contracts then correspond to transfer pricing rules between the two units that are only partially responsive to the units' information. Indeed, pooling contracts nullify the stake of collusion and can therefore be implemented under centralization, but the optimal contract in this case nevertheless entails full separation, as shown in Proposition 4.

When delegation involves full separation as well, the comparison between both structures is more complex. Denoting $W^{D^{\prime}}(\hat{q}, \bar{q})$ and $W^{c}(\hat{q}, \bar{q})$ the firm's profits under delegation and centralization, we have

$$
W^{C}(\hat{q}, \bar{q})=W^{D^{\prime}}(\hat{q}, \bar{q})+\nu\left(-1+\frac{\nu(2-\nu)}{(1-\nu)}\right) \Delta \theta(\hat{q}-\bar{q})
$$

We can summarize the comparison between both organizational forms as follows:

Theorem 4. There exists $\nu^{* *}<\nu^{*}$ such that delegation achieves a strictly higher profit than centralization with limits on communication if and only if $\nu \leq \nu^{* *}$.

${ }^{34} \mathrm{McAfee}$ and McMillan (1995) have already analyzed the same timing of coalition formation in a related model with a continuum of types. They have also shown that an increase in the length of the hierarchy increases the agency costs needed to get information on the production technology, even if intermediate layers do not have private information. 
Proof. See the Appendix.

For low (high) probabilities of having efficient agents in the organization, it becomes more (less) costly to obtain information under centralization than under delegation. Delegation imposes a large extra agency cost on the organization only when the double rent extraction becomes an important concern in the organization, i.e., only when $\nu$ is high. When $\nu$ is small, delegation still dominates centralization. The benefit of a nonanonymous organization outweighs the loss of control. ${ }^{35}$

Lastly, centralization with ex post participation constraints within the coalition (which is equivalent to centralization with verifiable information) is dominated by delegation with ex post participation constraints, since the latter may implement more flexible rules than the former, which always implements a pooling allocation (Proposition 7).

\section{Conclusion}

- We have shown that the delegation puzzle can be solved when both collusive behavior and limits on communication are simultaneously taken into account. Limits on communication impose an anonymity condition on the grand-contract. This anonymity creates some stakes for collusive behavior that undermines the efficiency of the centralized arrangement when agents are treated symmetrically. Under delegation, this anonymity is instead alleviated by design. Delegation takes advantage of the conftict between the agents coming from their asymmetric treatment in the organization.

Our results could be extended in several directions: substitutability between the agents' activities, asymmetry between agents, or correlation of types among agents. ${ }^{36}$ Importantly, since asymmetry in bargaining in the side contracting plays such an important role, it would be nice to understand how the principal can play on the authority relationship, the repeated relationship between agents, and other parameters of the underlying physical environment to affect this bargaining power to his benefit. ${ }^{37}$

\section{Appendix}

- Proof of Proposition 2. We solve the game backward. For a given grand-contract there is no loss of generality in looking for the best side contract within the class of direct mechanisms. When $A_{1}{ }^{\prime} \mathrm{s}$ type is $\theta_{1}$, the optimal side contract $\operatorname{SC}\left(\theta_{1}\right)$ is therefore the solution to the following program (hereafter denoted $\left(D\left(\theta_{1}\right)\right)$ ):

$$
\max _{s c} \nu\left(2 t\left(\phi\left(\theta_{1} \underline{\theta}\right)\right)-y_{2}\left(\theta_{1} \underline{\theta}\right)-\theta_{1} q\left(\phi\left(\theta_{1}, \underline{\theta}\right)\right)\right)+(1-\nu)\left(2 t\left(\phi\left(\theta_{1}, \bar{\theta}\right)\right)-y_{2}\left(\theta_{1}, \bar{\theta}\right)-\theta_{1} q\left(\phi\left(\theta_{1}, \bar{\theta}\right)\right)\right),
$$

subject to

$$
\begin{aligned}
& y_{2}\left(\theta_{1}, \underline{\theta}\right)-\underline{\theta} q\left(\phi\left(\theta_{1}, \underline{\theta}\right)\right) \geq y_{2}\left(\theta_{1}, \bar{\theta}\right)-\underline{\theta} q\left(\phi\left(\theta_{1}, \bar{\theta}\right)\right) \\
& y_{2}\left(\theta_{1}, \bar{\theta}\right)-\bar{\theta} q\left(\phi\left(\theta_{1}, \bar{\theta}\right)\right) \geq 0 .
\end{aligned}
$$

The first (second) of the above constraints is the incentive (participation) constraint of an efficient (inefficient) agent when facing the side contract offered by $A_{1}$ of type $\theta_{1}$.

In the process of delegation, the principal offers a mechanism that must be immune to the manipulation of $A_{1}$ 's report on all the information he has learned during the side-contracting stage of the game. There is

${ }^{35}$ Note, however, that if under centralization acceptance of the grand-contract takes place only after collusion, centralization is worse. This can easily be seen from Propositions 6 and 8 . Delegation with ex post participation constraints always does at least weakly better than centralization. For $v<v^{*}$, it does strictly better.

${ }^{36}$ See Laffont and Martimort (1997b) for the analysis of the case of centralization with conelation of types.

${ }^{37}$ See Laffont and Meleu (1997) for an analysis along these lines in a different model with hard information. 
no loss of generality for the principal $P$ to offer delegation-proof mechanisms such that $\phi\left(\theta_{1}, \theta_{2}\right)=\left(\theta_{1}, \theta_{2}\right)$ for all pairs $\left(\theta_{1}, \theta_{2}\right)$. The condition of optimality of this null-manipulation function can then be stated as follows:

Lemme Al. A grand-contract is delegation-proof if and only if it satisfies the following constraints:

$$
\begin{array}{cc}
2 t(\underline{\theta}, \underline{\theta})-2 \underline{\theta} q(\underline{\theta}, \underline{\theta}) \geq 2 t\left(\theta_{1}, \theta_{2}\right)-2 \underline{\theta} q\left(\theta_{1}, \theta_{2}\right) & \forall \theta_{1}, \theta_{2}, \\
2 t(\underline{\theta}, \bar{\theta})-\left(\underline{\theta}+\bar{\theta}+\frac{\nu}{1-\nu} \Delta \theta\right) q(\underline{\theta}, \bar{\theta}) \geq 2 t\left(\theta_{1}, \theta_{2}\right)-\left(\underline{\theta}+\bar{\theta}+\frac{\nu}{1-\nu} \Delta \theta\right) q\left(\theta_{1}, \theta_{2}\right) & \forall \theta_{1}, \theta_{2,} \\
2 t(\bar{\theta}, \underline{\theta})-(\underline{\theta}+\bar{\theta}) q(\bar{\theta}, \underline{\theta}) \geq 2 t\left(\theta_{1}, \theta_{2}\right)-(\underline{\theta}+\bar{\theta}) q\left(\theta_{1}, \theta_{2}\right) & \forall \theta_{1}, \theta_{2}, \\
2 t(\bar{\theta}, \bar{\theta})-\left(2 \bar{\theta}+\frac{\nu}{1-\nu} \Delta \theta\right) q(\bar{\theta}, \bar{\theta}) \geq 2 t\left(\theta_{1}, \theta_{2}\right)-\left(2 \bar{\theta}+\frac{\nu}{1-\nu} \Delta \theta\right) q\left(\theta_{1}, \theta_{2}\right) & \forall \theta_{1}, \theta_{2} .
\end{array}
$$

Proof. After having replaced the values of the transfers $y_{2}\left(\theta_{1}\right)$ and $\bar{y}_{2}\left(\theta_{1}\right)$ in the objective function of $\left(D\left(\theta_{1}\right)\right)$ when the incentive and participation constraints in $\left(D\left(\theta_{1}\right)\right)$ are binding, we simply write for each $\left(\theta_{1}, \theta_{2}\right)$ the conditions stating that the null-manipulation of report is optimal.

The optimal grand-contract offered by $P$ is therefore the solution to the following program:

$$
\max _{M}\left\{p^{2}(S(\underline{q})-2 \underline{t})+\nu(\mathrm{I}-\nu)\left(S\left(\hat{q}_{\mathrm{l}}\right)-2 \hat{t}_{\mathrm{t}}\right)+\nu(1-\nu)\left(S\left(\hat{q}_{2}\right)-2 \hat{t}_{2}\right)+(1-\nu)^{2}(S(\bar{q})-2 \bar{t})\right\}
$$

subject to $(30),(31),(32),(33)$,

$$
\begin{aligned}
& \underline{U}=\nu\left(2 \underline{t}-2 \underline{\theta} \underline{q}-\Delta \theta \hat{q}_{2}\right)+(\mathrm{I}-\nu)\left(2 \hat{t}_{2}-(\underline{\theta}+\bar{\theta}) \hat{q}_{2}\right) \geq 0, \\
& \bar{U}=\nu\left(2 \hat{t}_{1}-(\underline{\theta}+\bar{\theta}) \hat{q}_{\mathrm{t}}-\Delta \theta \bar{q}\right)+(1-\nu)(2 \bar{t}-2 \bar{\theta} \bar{q}) \geq 0 .
\end{aligned}
$$

where the latter two constraints are the interim participation constraints of the agent $A_{1}$ before he knows agent $A_{2}{ }^{1}$ s type when he is respectively efficient and inefficient. We can check that the following upward coalition incentive constraints are the only binding ones:

$$
\begin{aligned}
2 \underline{t}-2 \underline{\theta} \underline{q} & \geq 2 \hat{t}_{2}-2 \underline{\theta} \hat{q}_{2} \\
2 \hat{t}_{2}-(\underline{\theta}+\bar{\theta}) \hat{q}_{2} & \geq 2 \hat{t}_{1}-(\underline{\theta}+\bar{\theta}) \hat{q}_{1} \\
2 \hat{t}_{\mathrm{I}}-\left(\underline{\theta}+\bar{\theta}+\frac{\nu}{\mathrm{I}-\nu} \Delta \theta\right) \hat{q}_{1} & \geq 2 \bar{t}-\left(\underline{\theta}+\bar{\theta}+\frac{\nu}{1-\nu} \Delta \theta\right) \bar{q} .
\end{aligned}
$$

Moreover, the participation constraint of an inefficient middle principal is also binding, $\bar{U}=0$, and from that we deduce $\underline{U}=\Delta \theta\left(\nu \hat{q}_{1}+(1-\nu) \bar{q}\right)$. Inserting the values of the transfers into the principal's objective function and optimizing leads to the second-best outcome. In particular, $\hat{q}_{1}=\hat{q}_{2}$ is defined by (1.1). Q.E.D.

Proof of Proposition 6. We optinize the principal's problem subject to (3) (written with an anonymous transfer), (14), (19), and (20). When (19) and (20) are binding, (14) is automatically satisfied if $\hat{q} \geq \bar{q}$. Inserting the values of the transfers found when (3), (19), and (20) are binding into the principal's objective function. we find that the incentive-compatibility constraint $\hat{q} \geq \bar{q}$ is violated. Some bunching $\hat{q}=\bar{q}$ emerges at the optimum, which is then given by equation (10) and $\hat{q}^{c W}=\bar{q}^{c v}=q^{c W}$ defined in the proposition. Q.E.D.

Proof of Proposition 8. Inserting the value of $\bar{t}$, obtained when $2 \bar{t}-2 \bar{\theta} \bar{q} \geq 0$ is binding, into the delegationproofness constraint, we obtain the following inequality:

$$
2 \hat{t}-(\underline{\theta}+\bar{\theta}) \hat{q} \geq \frac{\nu}{1-\nu} \Delta \theta(\hat{q}-\bar{q})+\Delta \theta \bar{q} .
$$

Taking into account that $\hat{q} \supseteq \bar{q}$, comparing (A.) and the third constraint in (D) shows that (A.l) is the binding constraint characterizing $\hat{t}$. Similarly, the constraint $2 \underline{t}-2 \underline{\theta} q \geq 2 \hat{t}-2 \underline{\theta} \hat{q}$ and the participation constraint $2 \bar{t}-2 \bar{\theta} \bar{q} \geq 0$ are also binding at the optimum of $\left(D^{\prime}\right)$. It obtained above into the principal's objective function, we obtain 


$$
\begin{aligned}
W^{D^{\prime}}(\hat{q}, \bar{q})= & \nu^{2}\left(S(\underline{q})-2 \underline{\theta} \underline{q}-\Delta \theta \hat{q}-\Delta \theta \bar{q}-\frac{\mu}{1-\nu} \Delta \theta(\hat{q}-\bar{q})\right) \\
& +2 \nu(1-\mu)\left(S(\underline{q})-(\underline{\theta}+\bar{\theta}) \hat{q}-\Delta \theta \bar{q}-\frac{\nu}{1-\nu} \Delta \theta(\hat{q}-\bar{q})\right)+(1-\nu)^{2}(S(\bar{q})-2 \bar{\theta} \bar{q}) .
\end{aligned}
$$

Optimizing with respect to $q, \hat{q}$ and $\bar{q}$, we obtain (26) and (27). There is no bunching in the allocation when $\hat{q}>\bar{q}$, i.e., when

$$
1+\frac{\nu(2-\nu)(1-2 \nu)}{(1-\nu)^{3}}>\frac{\nu(3-2 \nu)}{2(1-\nu)^{2}}
$$

Simplifying, this condition becomes $2-5 y+\nu^{2} \geq 0$, i.e., $\mu \in\left[0, \nu^{*}\right]$ where $\nu^{*}=(5-\sqrt{17}) / 2$. Reoptimizing the principal's objective function when there is pooling $\hat{q}=\bar{q}_{1}$ we find (28). Q.E.D.

Proof of Theorem 4. When $-1+\nu(2-\nu) /(1-\nu)>0$. i.e., when $\nu \in\left[\nu^{*}, 1\right]$ with $\nu^{* *}=(3-\sqrt{5}) / 2$, the optimal separating contract under delegation (i.e., when $\nu \in\left[\nu^{* *}, \nu^{*}\right]$ ) gives a profit for the organization that is strictly dominated by the profit achieved under centralization for this schedule of outputs. Since this level is dominated by the optimal separating contract under centralization, the latter organization dominates.

For $\nu \in\left[\nu^{*}, 1\right]$, the optimal contract under delegation is a pooling one. It is therefore dominated by the optimal screening contract under centralization.

For $\nu \in\left[0, v^{* *}\right]$, the optimal contract under centralization is separating. It is dominated by the same schedule of outputs offered under delegation. Q.E.D.

\section{References}

Banman, S. "Agency Research in Managerial Accounting: A Survey." Journal of Accounting Literature, Vol. 1 (1982), pp. 154-213.

BaLliga, S. AND SJosTrom, T. "Decentralization and Collusion." Mimeo, Harvard University, 1996.

BARON, D.P. AND BESANKO, D. "Information, Control and Organizational Structure." Journal of Economics and Management Strategy, Vol. 1 (1992), pp. 237-275.

- AND — "Informational Alliances." Mimeo, Stanford University, 1995

Bolton, P. AND DEwatripont, M. "The Firm as a Communication Network." Quarterly Joumal of Economics, Vol. 109 (1994), pp. 809-839.

CALvo, G.A. AND WELlisz, S. "Supervision, Loss of Control and the Optimal Size of the Firm." Joumal of Political Economy. Vol. 86 (1978), pp. 943-952

Coleman, J. Foundations of Social Theory. Cambridge, Mass.: Harvard University Press, 1990.

CREMER, J. AND RIORDAN, M.H. "On Governing Multilateral Transactions with Bilateral Contracts." RAND Journal of Economics, Vol. 18 (1987), pp. 436-451.

Crozler, M. Le Phénomène Bureaucratique. Paris: Editions du Seuil, 1963.

Dalton, M. Men Who Manage. In M. Granovetter and R. Swedberg, eds., The Sociology of Economic Life. Boulder, Colo: Westview Press, 1959.

DYE, R.A. "Costly Contract Contingencies." International Economic Review, Vol. 26 (1985), pp. 233-250.

Eccles, R. "Transfer Pricing as a Problem of Agency." In J.W. Pratt and R.J. Zeckhauser, eds., Principals and Agents: The Structure of Business. Cambridge, Mass.: Harvard Business School Press, 1985.

FELLI, L. "Collusion in Incentive Contracts: Does Delegation Help?" Mimeo, London School of Economics, 1997.

FudenberG, D. AND LEvinE, D. "Repeated Games with Short-Run and Long-Run Players." Econometrica, Vol. 62 (1989), pp. 997-1039.

Grabard, A. "Maripulation of Voting Schemes." Econometrica, Vol. 41 (1973), pp. 587-601.

GLleERT, R. AND RIORDAN, M. "Regulating Complementary Rroducts: A Comparative Institutional Analysis." RAND Journal of Economics, Vol. 26 (1995), pp. 243-256

GOULDNER, A. "The Norm of Reciprocity." American Sociological Review, Vol. 25 (196I), pp. 161-179.

GREEN, J. AND LAFFONT, J.-J. "Characterization of Satisfactory Mechanisms for the Revelation of Preferences for Public Goods." Econometrica, Vol. 45 (1977), pp. 427-438.

Reiter, eds., Information, Incentives and Economic Mechanisms. Minneapolis: University of Minnesota Press, 1982.

- 2 AND - "Incentive Theory with Data Compression." In W.R. Heller, R.M. Starr, and R. Radner, eds., Uncertainty, Information and Communication. Cambridge: Cambridge University Press, 1986

Groves, T. "Incentives in Teams." Econometrica, Vol. 41 (1973), pp. 617-631. 
HART, O.D. AND MOORE, J. “Incomplete Contracts and Renegotiation.” Econometrica, Vol. 56 (1988), pp. 755-785.

Holmström, B. "The Firm as a Subeconomy." Mimeo, MIT, 1996.

LafFont, J.-I. AND MARTIMORT, D. “The Collusion-Proof Samuelson Conditions for Public Goods." Mimeo, IDEI, Toulouse, 1996.

- AND - "Collusion Under Asymmetric Information." Econometrica, Vol. 65 (1997a), pp. 875911.

AND - "Mechanism Design Under Collusion and Cortelation." Mimeo, IDEI, Toulouse, 1997b. And Maskin, E. "A Differential Approach to Dominant Strategy Mechanisms." Economerrica, Vol. $48(1980)$, pp. 1507-1520.

- AND MELEU, M. "Reciprocal Supervision, Collusion and Organizational Design." Scandinaviam Journal of Economics, Vol. 99 (1997), pp. 519-540.

MAChO-STADLER, I. AND PEREZ-CASTRILLO, D. "Centralized and Decentralized Contracts in a Moral Hazard Environment." Mimeo, Universidad Autonoma de Barcelona, 1990.

Martimort, D. "The Life Cycle of Regulatory Agencies: Dynamic Capture and Transaction Costs." Mimeo, Inra, Toulouse, 1996.

"A Theory of Bureaucratization Based on Reciprocity and Collusive Behavior." Scandinavian Journal of Economics, Vol. 99 (1997), pp. 555-579.

MaSKIN, E. AND TrRole, J. “The Principal-Agent Relationship with an [nformed Principal, I: The Case of Private Values." Econometrica, Vol. 58 (1990), pp. 379-410.

- AND —. "The Principal-Agent Relationship with an Informed Principal, II: Common Values." Econometrica, Vol. 60 (1992), pp. 1-41.

MCAFEE, R.P. AND MCMillan, J. "Otganizational Diseconomies of Scale." Journal of Economic and Management Strategy, Vol. 4 (1995), pp. 399-426.

Melimad, N., MookherJeE, D., and ReicheLstein, S. "A Theory of Responsibility Centers." Journal of Accounting and Economics, Vol. 15 (1992), pp. 445-484.

$\longrightarrow$ - - AND - "Hierarchical Decentralization of Incentive Contracts." RAND Journal of Economics, Vol. 26 (1995), pp. 654-672.

Mirrleges, J.A. "The Optimal Structure of Incentives and Authority within an Organization." Bell Journal of Economics, Vol. 7 (1976), pp. 105-131.

MOOKHERJEE, D. AND REICHELSTEIN, S. “Dominant Strategy [mplementation of Bayesian Incentive Compatible Allocation Rules." Journal of Economic Theory, Vol. 56 (1992), pp. 378-399.

MYERsoN, R.B. "Incentive Compatibility and the Bargaining Problem." Econometrica, Vol. 47 (1979), pp. $61-73$.

QraN, Y. "Incentives and Loss of Control in Optimal Hierarchy." Review of Economic Studies, Vol. 61 (1994), pp. 527-544.

RADNER, R. "The Organization of Decentralized Information Processing." Econometrica, Vol. 61 (1993), pp. 1109-1146.

StigliTZ, J.E. Whither Socialism Cambridge, Mass.: MIT Press, 1994.

TiRoLE, J. "Hierarchies and Bureaucracies: On the Role of Collusion in Organizations." Journal of Law, Economics and Organization, Vol. 2 (1986), pp. 181-214.

- "Collusion and the Theory of Organizations." In J.-J. Laffont, ed., Advances in Economic Theory, Vol. 2. Cambridge: Cambridge University Press, 1992.

VAN ZANDT, T. "The Scheduling and Organization of Periodic Associative Computations." Mimeo, Princeton University, 1996.

Wrllamson, O. "Hierarchical Control and the Optimal Firm Size." Jourmal of Political Economy, Vol. 75 (1967), gp. 123-138.

The Economic Institutions of Capitalism. New York: Free Press, 1985.

Wentrobe, R. AND Breton, A. "Organizational Structure and Ptoductivity." American Economic Review, Vol. 76 (I986), pp. 530-538. 